\title{
RELACIÓN MUJER Y BIOTECNOLOGÍA: APROXIMACIÓN AL IMPACTO DE LA BIOÉTICA
}

\author{
Carolina Valdebenito*, Alexis Lama** y Fernando Lolas ${ }^{* * *}$
}

Resumen: En este ensayo se reflexiona sobre la estructuración del ethos cultural latinoamericano que construye la imagen social de la mujer. Se intenta determinar cuál es el impacto de la biotecnología, específicamente de los anticonceptivos y de la reproducción asistida, en la construcción de esta imagen y, finalmente, se proponen vías para la reflexión bioética en temas que afectan a la mujer, principalmente a partir del caso chileno.

Palabras clave: bioética, género, biotecnología, imagen social

\section{RELATION BETWEEN WOMAN AND BIOTECHNOLOGY: AN APPROACH TO THE BIOETHICS IMPACT}

Abstract: This essay reflects on the Latin American cultural matrix from which the social woman image is built. This paper tries to determine what is the impact of biotechnology, specifically the role of contraception and assisted reproduction in building the woman image. Finally, some ways for bioethical reflection are proposed in relation to ethical issues which affect women, mainly in the Chilean context.

Key words: bioethics, gender, biotechnology, social image

\section{RELAÇÃO MULHER E BIOTECNOLOIGA: APROXIMAÇÃO AO IMPACTO DA BIOÉTICA}

Resumo: Neste ensaio reflete-se sobre a estruturação do ethos cultural latino-americano que constroi a imagem social da mulher. Procura-se determinar qual é o impacto da biotecnologia, especificamente dos anticoncepcionais e da reprodução assistida, na construção desta imagem. Finalmente, se propõe caminhos de reflexão bioética em temas realcionados com a mulher, principalmente a partir do caso chileno.

Palabras chave: bioética, gênero, biotecnologia, imagem social

\footnotetext{
* Antropóloga. Magíster en Salud Pública. Investigadora del Centro Interdisciplinario de Estudios en Bioética (CIEB), Universidad de Chile. Chile

** Cardiólogo. Director de la Escuela Medicina, Universidad Andrés Bello. Chile

*** Psiquiatra. Director del Centro Interdisciplinario de Estudios en Bioética (CIEB), Universidad de Chile. Chile

Correspondencia: valdebec@chi.ops-oms.org
} 


\section{Introducción}

Los avances biotecnológicos han creado un nuevo escenario para la mujer. Uno de los desarrollos científicos más significativos ha sido, sin duda, la aparición de los métodos anticonceptivos; ellos influyeron en el rol social de la mujer, porque crearon una disociación entre la satisfacción sexual de la mujer y su capacidad reproductora.

Este ensayo reflexiona acerca de la estructuración del ethos cultural latinoamericano que construye la imagen social de la mujer; intenta establecer cuál es el impacto de la biotecnología, específicamente de los anticonceptivos y de la reproducción asistida, en la construcción de esa imagen y, finalmente, propone vías para la reflexión bioética en temas que afectan a la mujer, principalmente a partir del caso de Chile.

\section{La influencia del ethos cristiano en la representación social de la mujer}

La representación social de la mujer en Latinoamérica está vinculada al ethos cristiano occidental(1), que se caracteriza por considerar al humano -y especialmente a la mujer-como un ser de naturaleza pecadora; en consecuencia, debe sufrir constantemente el castigo y el sacrificio. Éstos se expresan notoriamente a través de la represión de la sexualidad y, más aún, de la sexualidad femenina(2).

No es extraño que dentro de los valores inculcados se promueva la virginidad de la mujer hasta el matrimonio. Sin embargo, se debe destacar que no siempre ha sido así. En las sociedades precolombinas, si bien existía un poder jerarquizado, también había una división del trabajo que respetaba la posición de la mujer en la sociedad. Por otra parte, en las primeras religiones existía una fuerte presencia de la divinidad femenina, relacionada justamente con la fertilidad, el abrigo y la protección de la sociedad. Con el cristianismo la mujer es relegada al último peldaño de la sociedad; ella es interpretada como el origen del pecado. Debemos recordar el rol de Eva en la creación del mundo que describe la Biblia.

La Torá, por otra parte, relata que después que Dios creó al primer hombre lo durmió y separó de él a quien sería su esposa, Javá, pues él había visto que estaba solo y necesitaba una compañía. A Javá la Torá la llama "ézer kenegdó", es decir, una ayuda para él. De aquí que para que el hombre pueda cumplir correctamente su función en este mundo necesita a la mujer. En Génesis 2:23, señala: "Adam dijo: esta vez, este es hueso de mis huesos y carne de mi carne". Según la Torá esta es la razón por la que la mujer necesita del hombre para poder llevar a cabo su función y cumplir, junto con él, el propósito de la vida.

La religión musulmana señala que Alá ordenó a las esposas del Profeta y a las esposas de los creyentes que permanecieran en sus hogares, vistieran la hiyab (pañuelo o velo para la cabeza) y no mostraran sus encantos a hombres que no sean familiares con los que se puedan casar (mahram), pues esto conduce a la promiscuidad, plaga de la sociedad.

Es importante que nos detengamos en estos aspectos religiosos, pues será el discurso oficial de la Iglesia sobre el papel de la mujer el que influirá en la manera de interpretar su actuación y rol social en Latinoamérica.

El cristianismo produjo varios efectos en la representación social de la mujer, desde el rechazo de la sexualidad femenina hasta la proliferación de místicas, como Hildegard de Bingen, Santa Clara, Santa Catalina de Siena o Santa Isabel de Portugal. Sin embargo, debemos admitir que no todas las mujeres que entraban en el convento lo hacían por vocación. Un 
buen número de jóvenes eran donadas a los conventos por sus padres en los testamentos así como numerosas viudas los escogían como retiro. Desde el siglo XII encontramos algunas mujeres que adoptan formas de vida religiosa alejadas del convento. Es el caso de Christina de Markyate, en el siglo XII, al huir de un matrimonio no deseado, y su estancia por vida en una ermita donde tendrá algunas visiones. En los siglos XIV y XV se desarrollará el fenómeno de las emparedadas, mujeres que se introducían en una celda cuya puerta era tapiada. También se encuentran grupos que participaron en las órdenes mendicantes como terciarias. Algunas mujeres medievales no se conformaban con la religión tradicional y buscaban nuevos caminos como el misticismo.

Las experiencias místicas medievales son muy numerosas, pudiendo citar a Margarita de Ypres, Beatriz de Nazaret, Ángela de Foligno o Catalina de Siena. Ellas reivindican su derecho a amar a Dios sin intermediarios y ser amadas por Él del mismo modo. Una pretensión de libertad que rompía con la rigidez de la iglesia ortodoxa y que llevará a numerosas mujeres a la hoguera, víctimas de la Inquisición.

La religión judeocristiana y, en general, las religiones monoteístas nos ofrecen una descripción de cómo las mujeres quedaron excluidas del proceso de creación de símbolos: de la transición desde la naturaleza a la cultura. El monoteísmo borró, poco a poco, el importante papel desempeñado por las mujeres en los cultos primitivos e instauró una religión patriarcal, en cuanto a Dios se le representa como masculino, que habla y pacta sólo con varones (como queda patente en el rito de iniciación exigido por la religión judía -la circuncisión- que atañe sólo a los varones). Luego de eso queda impreso en la sociedad que la mujer es el origen del pecado; es lo concupiscente y, por tanto, se le debe controlar y dominar.
La sexualidad, entendida como proceso biológico del cual se puede obtener placer, es censurada en las sociedades latinoamericanas por la condición pecadora de la mujer. Por lo tanto, mientras más esfuerzos se hagan por controlar el goce sexual más cerca se está de la rendición espiritual. Ejemplo de ello es la exaltación de las figuras religiosas consagradas a lo espiritual sin conocer los placeres de la carne, o que han renunciado a ellos para seguir el camino espiritual.

La sexualidad tiene connotaciones sociales que se alejan de la reproducción y se relacionan con el empoderamiento social. En las sociedades latinoamericanas el hombre es poseedor de su sexualidad y puede administrarla sin censuras; es también quien expresa su poder social con vehemencia sobre las mujeres. Esta actitud falocentrista se sostiene en la noción de que el hombre es superior a la mujer.

Las primeras interpretaciones arqueoantropológicas mostraron al hombre en un rol social de cazador y constructor de herramientas, mientras que la mujer estaba a cargo de las tareas de recolección de alimentos y cuidado de los hijos. Se produce así la disociación entre (hombre)cultura y (mujer)naturaleza. Si la mujer se asocia a la naturaleza, entonces ésta debe ser dominada y controlada por la cultura.

\section{Desarrollo biotecnológico: impacto en la representación social de lo femenino}

Desde la creencia que el doble cromosoma $\mathrm{XX}$ era una deformación del XY, la mujer ha sido confinada al ámbito privado, considerándola un ser inferior. En el siglo XVII, Anton van Leeuwenhoek, inventor del microscopio, consideró que los espermatozoides eran los exclusivos causantes de la vida, teoría que sólo cambiaría en 1827 cuando fue descubierto el óvulo. Biológicamente, hasta el siglo XIX (de acuerdo con los descubrimientos de la época) la mujer no tenía 
ningún mérito para establecer un rol social que no fuese relacionado con el cuidado de las crías imitando a las demás especies animales.

El avance de la biotecnología ha liberado a la mujer de sus obligaciones tradicionales y ha evidenciado su capacidad en otros ámbitos, fenómeno que la sitúa en igualdad de condiciones frente al hombre. También, desde otro campo de sujeción, los anticonceptivos y la reproducción asistida han disociado su sexualidad de su capacidad reproductiva, lo que ha redundado en mayores espacios de libertad.

Sin embargo, en las primeras civilizaciones o grupos humanos, la posibilidad de embarazo no fue impedimento para el goce sexual de las mujeres ni tampoco para desempeñar tareas de alto rendimiento, como las de recolección o el manejo de embarcaciones. Por lo tanto, parece válido considerar que el cambio en la percepción de lo femenino en Latinoamérica sucede con el advenimiento de la cultura cristiano-occidental, que sitúa a la mujer en el ámbito privado, justificando esto por su condición reproductora. Este cambio se vincula con la interpretación de lo femenino como lo pecaminoso y salvaje, susceptible de ser controlado y subyugado por un ser racional como es el hombre.

Lo que parece acompañar permanentemente a la expresión de la sexualidad de la mujer es el aborto. Ante agresiones sexuales o condiciones no favorables para la crianza de los hijos, mujeres de distintas épocas -ancianas y jóvenes- han conocidos formas de poner término a embarazos no deseados.

\section{Biotecnología y argumentos éticos: influencia en la representación social de la mujer}

El desarrollo biotecnológico ha afectado la existencia de las mujeres en la sociedad actual. La agresión, tanto corporal como mental, de un aborto fue reemplazada por métodos menos agresivos, como los anticonceptivos. Los métodos de control natal no fueron el único avance que afectó la representación social de la mujer, también la fertilización in-vitro hizo lo propio, dando una oportunidad a aquellas mujeres que no podían engendrar.

Como resultado de estos avances, hay una nueva relación entre la mujer y su naturaleza biológica, tradicionalmente relacionada con la maternidad. Hoy la mujer puede decidir si va a engendrar hijos y cuántos y en qué condiciones; incluso, mediante pruebas genómicas, puede, eventualmente, generar una selección prenatal.

Sin duda, los avances científicos tienen siempre un impacto social, ya sea en cuanto se pueden rechazar o abrazar. No son escasos los debates éticos que involucra la capacidad de la mujer de dar a luz, sin embargo, pocas veces es convocada o escuchada en la toma de decisiones $o$ en las legislaciones al respecto.

\section{Feminismo y biotecnología: el caso chileno}

Los problemas bioéticos no sólo se asocian a los usos y destinos del conocimiento científico, sino también a las condiciones sociales en que se generan y las consecuencias que producen. Aunque en algunos de los países latinoamericanos el aborto está prohibido, es más fácil para una adolescente de buena situación económica entrar a una clínica privada por apendicitis y salir con un aborto seguro, que para otra en situación marginal tener un hijo-que no puede alimentar- $\mathrm{o}$ someterse a riesgosas prácticas de aborto artesanal que le producirán infertilidad o la muerte.

A su vez, la fertilización asistida genera grandes contradicciones, pues, por la magnitud de sus costos, no son muchos los que pueden acceder a estos programas. En el ensayo "Los Derechos de la Mujer en Chile: Un Reporte Sombra(3)" se subraya que la mujer chilena 
tiene dos situaciones desventajosas con las cuales convivir: con el hombre y con mujeres de niveles socioeconómicos más altos.

Dado que las posibilidades de regulación en temas de esta envergadura son limitadas, la bioética tiene un deber indiscutible respecto del rol de la mujer en la sociedad y del empoderamiento de su propio cuerpo. La biotecnología no sólo produce temas para debatir en salas de reuniones, sino que genera grandes controversias sociales.

Producto de la situación económica, la incorporación a la fuerza laboral, el laicismo de las nuevas generaciones y la comodidad que entrega la tecnología, la representación social de la mujer ha cambiado: no sólo ser dueña de casa es posible, también se puede trabajar, ir al gimnasio, tener esposo y cuidar del hogar. Sin embargo, cabe reflexionar también acerca de la situación de quienes no tienen los medios para acceder a los beneficios de la tecnología. Por ejemplo, aunque en Chile existan prohibiciones legales contra el aborto, se producen 160.000 al año en forma clandestina, lo que representa una situación de riesgo para la vida y salud de la mujer. Se estima que un $35 \%$ de los embarazos terminan en aborto y un $40 \%$ de las mujeres que abortan son menores de 18 años. Tres abortos resultan en la hospitalización por complicaciones y es la causa principal del $30 \%$ de las muertes maternas.

Adicionalmente, las que asisten a un hospital de emergencia, pues están en peligro de morir por una mala intervención, son discriminadas y estigmatizadas por los profesionales de la salud que ahí las atienden, sometiéndolas a duros tratos y a descalificaciones personales.

En la sociedad contemporánea existen al menos dos posibilidades para que la mujer viva los avances de la biotecnología. Puede hacer uso de ella fuera de los límites de normalización legislativa y moral del contexto sociocultural, o someterse a la legislación y tomar de los avances tecnológicos sólo lo que no atente contra su moralidad cristiano-occidental.

Es interesante recordar a Jonas, quien reflexiona sobre la moralidad en la técnica. Toda aplicación técnica es cultura y, en este sentido, toda utilización de la ciencia y de la técnica tiene un marco regulatorio vinculado con la religión, las creencias y las ideologías. Esto permitiría entender que desarrollos como el control natal o la "píldora del día después" requieren de un sustrato cultural que los validen para ser aceptados, de manera de no atentar contra los principios sociales. El problema es que los abortos se siguen produciendo, mientras la sociedad hace consenso y las vidas de niños y mujeres siguen en riesgo.

Sin embargo, la reflexión no debe quedar limitada a los beneficios de la biotecnología en la capacidad reproductiva de la mujer. Hoy existe un empoderamiento de la mujer con su cuerpo, lo que incluye, por cierto, su capacidad reproductiva, que debe ser replanteada y reestudiada.

La bioética tiene un papel muy importante en discernir cómo la sociedad incorpora los cambios tecnocientíficos y, en consecuencia, cómo afecta esto a la imagen que se tiene de la mujer como persona y como interlocutor válido. Pero también debe incluir el examen y discusión de los alcances sociales que tendrá la incorporación de innovaciones tecnológicas en entornos aún conservadores.

\section{Agradecimientos}

Artículo realizado en el marco del proyecto: Representation of genomics research among Latin American laymen and bioethics: a inquiry into the migration of knowledge and its impact on underdeveloped communities. Department of Energy, DOE \# DE-FG02-02ER63435, Centro Interdisciplinario de Estudios en Bioética (CIEB), Universidad de Chile. 


\section{Referencias}

1. Morandé P. Cultura y modernización en América Latina. Santiago de Chile: Cuaderno del Instituto de Sociología de la Pontificia Universidad Católica de Chile; 1984.

2. Girard R. La violencia y lo sagrado. Barcelona: Anagrama; 1983.

3. Centro Legal para Derechos Reproductivos. Los Derechos de la Mujer Chile: Un Reporte Sombra. New York: Centro Legal para Derechos Reproductivos y Políticas Públicas; 1999. [Sitio en Internet] Disponible en: http://www.reproductiverights.org Último acceso en octubre de 2006.

\section{Bibliografía}

Álvarez G, Álvarez A, Facuse M. Discurso, Cultura, Salud: La Noción de Interculturalidad en Salud. Atenea 2002; 486(1): 79-90.

Cruz-Coke MR. Normas bioéticas de UNESCO para evitar practicas eugenésicas en investigaciones biomédicas. Revista Médica de Chile 2000; 128(6):1-6.

Matamala M. Discriminación en las mujeres en el sistema de instituciones de salud previsional. Serie Género y Reforma de Salud No 1. Santiago de Chile: OPS/OMS; 2002.

Montecino S. De la Mujer al Género: Implicaciones Acádemicas y Teóricas. En: Rebolledo L, (ed.) Mujer y Género: Nuevos Saberes en las Universidades Chilenas. Santiago de Chile: Bravo y Allende Editores; 1995.

Montecino S, Rebolledo L. Los Estudios de la Mujer o de Género en el Universo Académico Chileno. En: Rebolledo L, (ed.) Mujer y Género: Nuevos Saberes en las Universidades Chilenas. Santiago de Chile: Bravo y Allende Editores; 1995.

Montecino S, Castro R, De la Parra MA, (eds.) Mujeres, espejos y fragmentos: antropología del género y salud en Chile del siglo XXI. Santiago de Chile: Aconcagua; 2003.

Servicio Nacional de la Mujer. Mujer Chilena Hoy: Datos Estadísticos (Proyección). [Sitio en Internet] Disponible en: http://www.sernam.cl/basemujer/index.htm Último acceso en octubre de 2006.

Tajer D. Construyendo una agenda de género en las políticas publicas en salud. En: Políticas Públicas, Mujer y Salud. Popayán: Ediciones Universidad Nacional del Cauca y RSMLAC; 2004: 27-39.

Unidad Mujer y Desarrollo. Entender la pobreza desde la perspectiva de género. Santiago de Chile: CEPALUNIFEM- República de Italia; 2004.

Recibido el 26 de enero de 2006.

Aceptado el 03 de marzo de 2006. 